\title{
The association between coffee consumption and bladder cancer in the bladder cancer epidemiology and nutritional determinants (BLEND) international pooled study
}

\author{
Evan Yi-Wen $\mathrm{Yu}^{1,2} \mathbb{D} \cdot$ Anke Wesselius $^{1} \cdot$ Frits van Osch ${ }^{1,3} \cdot$ Mariana Carla Stern $^{4} \cdot$ Xuejuan Jiang $^{4} \cdot$ Eliane Kellen $^{5}$. \\ Chih-Ming Lu ${ }^{6} \cdot$ Hermann Pohlabeln $^{7}$. Gunnar Steineck ${ }^{8}$. James Marshall ${ }^{9} \cdot$ Mohamed Farouk Allam $^{10}$. \\ Carlo La Vecchia ${ }^{11} \cdot$ Kenneth C. Johnson ${ }^{12} \cdot$ Simone Benhamou $^{13} \cdot$ Zuo-Feng Zhang $^{14} \cdot$ Cristina Bosetti $^{15}$. \\ Jack A. Taylor ${ }^{16} \cdot$ Maurice P. Zeegers $^{1,2}$
}

Received: 25 January 2019 / Accepted: 25 May 2019 / Published online: 30 May 2019

(c) The Author(s) 2019

\begin{abstract}
Background Inconsistent results for coffee consumption and bladder cancer (BC) risk have been shown in epidemiological studies. This research aims to increase the understanding of the association between coffee consumption and BC risk by bringing together worldwide case-control studies on this topic.

Methods Data were collected from 13 case-control comprising of 5,911 cases and 16,172 controls. Pooled multivariate odds ratios (ORs), with corresponding 95\% confidence intervals (CIs), were obtained using multilevel logistic regression models. Furthermore, linear dose-response relationships were examined using fractional polynomial models.

Results No association of BC risk was observed with coffee consumption among smokers. However, after adjustment for age, gender, and smoking, the risk was significantly increased for never smokers (ever vs. never coffee consumers: OR ${ }_{\text {model } 2} 1.30$,

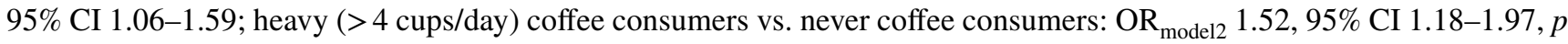
trend $=0.23$ ). In addition, dose-response analyses, in both the overall population and among never smokers, also showed a significant increased $\mathrm{BC}$ risk for coffee consumption of more than four cups per day. Among smokers, a significant increased $\mathrm{BC}$ risk was shown only after consumption of more than six cups per day.

Conclusion This research suggests that positive associations between coffee consumption and BC among never smokers but not smokers.
\end{abstract}

Keywords Bladder cancer $\cdot$ Coffee consumption $\cdot$ Smoking $\cdot$ Dose-response analyses $\cdot$ Population-attributable risk

$\begin{array}{ll}\text { Abbreviations } \\ \text { BC } & \text { Bladder cancer } \\ \text { IARC } & \text { International Agency for Research on Cancer } \\ \text { BLEND } & \begin{array}{l}\text { Bladder cancer epidemiology and nutritional } \\ \text { determinants }\end{array} \\ \text { FFQ } & \text { Food frequency questionnaires } \\ \text { OR } & \text { Odds ratio } \\ \text { CI } & \text { Confidence interval } \\ \text { POR } & \text { Pooled odds ratio }\end{array}$

Electronic supplementary material The online version of this article (https://doi.org/10.1007/s10552-019-01191-1) contains supplementary material, which is available to authorized users.

Evan Yi-Wen Yu

evan.yu@maastrichtuniversity.nl

Extended author information available on the last page of the article
CYP1A2 Cytochrome P450 1A2

PAHs Polycyclic aromatic hydrocarbons

ATM Ataxia-telangiectasia mutated

PAR Population-attributable risk

BMI Body mass index

SES Socioeconomic status

\section{Introduction}

Bladder cancer (BC) is the most common malignancy of the urinary tract and the seventh cause of death from cancer (2.8\% of all cancer deaths), with nearly 430,000 new diagnoses and 165,000 deaths per year worldwide [1, 2]. Threequarters of all BC cases occur in men [3], and most BC cases occur in the United States, Canada, and the European Union [4-7]. As with many solid tumors, BC incidence increases 
with age and it rarely occurs before the age of 40-50 years [8]. Given that this cancer is easy to relapse, $\mathrm{BC}$ is reported to be the most expensive life-time treatment of all cancers raging from $€ 80,000$ to $€ 160,000$ per patient [9]. The strongest risk factors for $\mathrm{BC}$ occurrence, such as tobacco smoking and harmful chemicals [10], have long been identified. However, as the bladder is an excretory organ, the role of fluid consumption in the development of BC could also be important.

Coffee is one of the most consumed beverages in the world. Since early 1970s, the possible relationship between coffee consumption and $\mathrm{BC}$ has been of considerable interest, when Cole et al. [11] suggested for the first time that coffee was a potential risk factor for BC. The International Agency for Research on Cancer (IARC) Monographs Programme in 1991 stated that there was limited evidence on the effect of coffee consumption on the BC risk and subsequently classified coffee as "possibly carcinogenic" (group 2B; Monographs Volume 51) [12]. Since then, several epidemiological studies focused on the relationship between coffee consumption and $\mathrm{BC}$, however, results remained inconclusive [13-27]. In May 2016, a subsequent IARC Working Group of 23 scientists from 10 countries met to evaluate the carcinogenicity of drinking coffee and concluded that: "no consistent evidence of an association with drinking coffee, or of an exposure-response gradient". This conclusion was based on evidence from 10 cohort studies and several population-based case-control studies conducted in Europe, the United States, and Japan [28]. An explanation for this inconsistency may be that previous studies on the relation between coffee consumption and $\mathrm{BC}$ risk lacked sufficient sample size to identify a significant association. In addition, since heavy coffee consumption is shown to be strongly associated with tobacco smoking [29], positive associations reported in some studies could possibly have been due to inadequate control for tobacco smoking. Moreover, several studies showed smoking to be interactive with caffeine in coffee [30-35], and, thereby, lead to misleading results in un-stratified analysis on the relation between coffee consumption and BC risk.

The present study aims to update the understanding and find more conclusive answers on the influence of coffee consumption on the $\mathrm{BC}$ risk by bringing together available case-control studies on the topic including almost 6,000 BC cases.

\section{Methods}

\section{Study population}

Data were derived from the BLadder cancer Epidemiology and Nutritional Determinants study (BLEND). BLEND is a large international epidemiology consortium aimed to pool data from available epidemiological studies on diet and BC. For the present study, 13 case-control studies (including 5,911 cases/16,172 controls), originated from nine different countries in three continents (i.e., Europe, North America, and Asia) had sufficient information on coffee consumption to be eligible for inclusion. BC cases were diagnosed and histologically confirmed through each study center of the included individual studies, with International Classification of Diseases (ICD) nine or ten. Most of the BC cases were identified in 1990s.

\section{Data collection and coding}

Details on the methodology of the BLEND consortium have been described elsewhere [36]. Taking into account the local context of the included studies, different dietary assessment methods were adopted: (1) self-administrated food frequency questionnaire (FFQ) were used in Germany-1 [37], USA-2 [38], Canada-1 [39], France-1 [40], USA-3 [41], USA-4 [42]; (2) FFQ administered by a trained interviewer were used in USA-1 [43], Belgium-1 [44], China-1 [45], Sweden-1 [46], Spain-1 [47], Italy-1 [48], Italy-2 [49]. Coffee consumption was categorized using the hierarchal Eurocode 2 food coding system developed by the European Union [50]. To obtain unified consumption across studies, weekly, monthly, or yearly coffee cups were converted to daily cups of coffee consumption.

In addition to information on coffee and other dietary intake data, the BLEND dataset also included data on: study characteristics (design, method of dietary assessment, recall time of dietary consumption, and geographical region), participant demographics (age and gender), smoking status, and smoking pack-years.

\section{Statistical analyses}

To assess the influence of coffee consumption on the BC risk, multilevel logistic regression analyses were used to estimate the pooled odds ratios (ORs) and 95\% confidence intervals (CIs). Coffee consumption was expressed as: (1) ever (individuals who drank coffee $>0$ cup/day) or never consumption; (2) based on the available data, coffee consumption was divided into six categories: never, 0-1 cup/ day, 1-2 cups/day, 2-3 cups/day, 3-4 cups/day, and more than four cups/day; (3) caffeinated or decaffeinated coffee consumption. In addition, standardized analysis on coffee cup size was performed. For this we transformed a United States (U.S.) cup size to a $237 \mathrm{ml}$ coffee cup size according to U.S. Food and Drug Administration [51] and an Asian cup size to a $500 \mathrm{ml}$ cup size according to the questionnaire used in the study of Lu et al. [45]. 
The logistic regression models used never coffee consumers as the reference group and were computed as "crude model" (model 1), adjusted for age, gender, smoking (model 2), or fully adjustment (model 3) additionally adjusted other fluid consumption (i.e., water, liquid milk, tea, alcohol, carbonated drink, and juice). Smoking was defined as: 0 (never smokers); 1 [current light smokers (i.e., smoking less than 20 pack-years)]; 2 (current heavy smokers (i.e., smoking more than 20 pack-years)); 3 (former light smokers (i.e., smokers who ceased smoking over 1 year and smoked less than 20 pack-years)]; 4 [former heavy smokers [i.e., smokers who ceased smoking over 1 year and smoked more than 20 pack-years)]. In addition, the effect of ever versus never coffee consumption was also assessed using a meta-analysis approach; for this, pooled ORs (PORs) and 95\% CIs were calculated by using a random-effect model stratified by geographical regions (i.e., Europe, North America and Asia) and study designs (i.e., hospital-based case-control studies and population-based case-control studies). Due to the lack of data, the influence of caffeine on BC risk was only assessed by comparing ever (caffeinated vs. decaffeinated) versus never coffee consumers based on multilevel logistic regression (model 2 ). To understand the relevance of the effect modification, the interaction terms between coffee consumption and age, gender, smoking status with pack-years were added to the model 2. $P$ interaction $<0.10$ was considered statistically significant where upon analyses were stratified for the covariate of interest to understand the relevance of the effect modification.

In our secondary analysis, a potential dose-response relationship between coffee consumption and $\mathrm{BC}$ was assessed by using fractional polynomial regression, in which the best fitting second order fractional polynomial regression model was defined as the model with the lowest deviance $[52,53]$. A likelihood ratio test was used to assess the difference between the nonlinear and linear models to test for nonlinearity [54]. The results of the dose-response analyses were presented for each one coffee cup/day increment up to ten cups/day with stratification by smoking status (i.e., ever smokers and never smokers) and (i.e., hospital-based case-control studies and populationbased case-control studies). Adjustments (model 2) were made for age, gender, and smoking (in overall population).

Finally, the population-attributable risk (PAR) of heavy coffee consumption (i.e., $>4$ cups/day) on BC risk was estimated for Europe and North America, using the pooled risk estimates and the proportion of $\mathrm{BC}$ incidence in the population of interest.

All statistical analyses were performed with STATA version 14 SE (Stata Corporation, Texas, USA). $P$ values below 0.05 were considered statistically significant.

\section{Results}

\section{Baseline characteristics}

The baseline characteristics of the study population are shown in Table 1. Of more than 22,000 participants, 5,911 cases of BC (4,639 men, 1,272 women) were identified. The median age at baseline was 61.4 years for cases and 57.2 years for controls, respectively. Approximately $35 \%$ of participants reported drinking coffee more than four cups per day, with an average consumption of four cups/day overall. At baseline, a higher coffee consumption was observed among smokers (five cups/day) compared to never smokers (three cups/day). In addition, coffee consumption showed strong interaction with smoking status as well as packyears ( $p$ interaction: 0.001 and 0.042 , respectively), while not interaction was found with age ( $p$ interaction: 0.17 ) and gender ( $p$ interaction: 0.16 ).

\section{Associations between coffee consumption and BC risk}

\section{Ever versus never coffee consumption}

The results comparing ever versus never coffee consumers are shown in Table 2 and Fig. 1. Overall, after adjustment for possible confounders, no statistically significant difference in BC risk could be observed between coffee consumers versus never coffee consumers $\left(\mathrm{OR}_{\text {model } 2} 1.11,95 \% \mathrm{CI}\right.$ 0.98-1.26; $\left.\mathrm{OR}_{\text {model } 3} 1.09,95 \% \mathrm{CI} 0.94-1.25\right)$. Among never smokers, a statistically significant association between coffee consumption and the risk of $\mathrm{BC}$ was found after further adjustment $\left(\mathrm{OR}_{\text {model2 }} 1.30,95 \% \mathrm{CI} 1.06-1.59\right.$; $\mathrm{OR}_{\text {model3 }}$ $1.31,95 \%$ CI 1.03-1.66). For smokers, no significant association was observed comparing ever versus never coffee consumers. However, the estimates for former light smokers showed to be slightly higher than the estimates for other smokers. In addition, the meta-analysis stratified by geographical regions presented similar PORs based on model 2 (POR $_{\text {Overall }} 1.11,95 \%$ CI 0.96-1.25; $\mathrm{POR}_{\text {Europe }} 1.13,95 \% \mathrm{CI}$

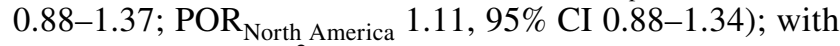
low heterogeneity $\left(I^{2}=0.0 \% ; p=0.57\right)$.

\section{Categories of coffee consumption with BC risk}

The results of multilevel logistic regressions for subsequent categories of coffee consumption are shown in Table 2. Overall, coffee consumption of more than four cups/day results in an increased BC risk of 1.27 (95\% CI 1.11-1.46, $p$ trend $=0.05$, model 2) compared to never coffee consumers. A similar increased risk was observed among never smokers 


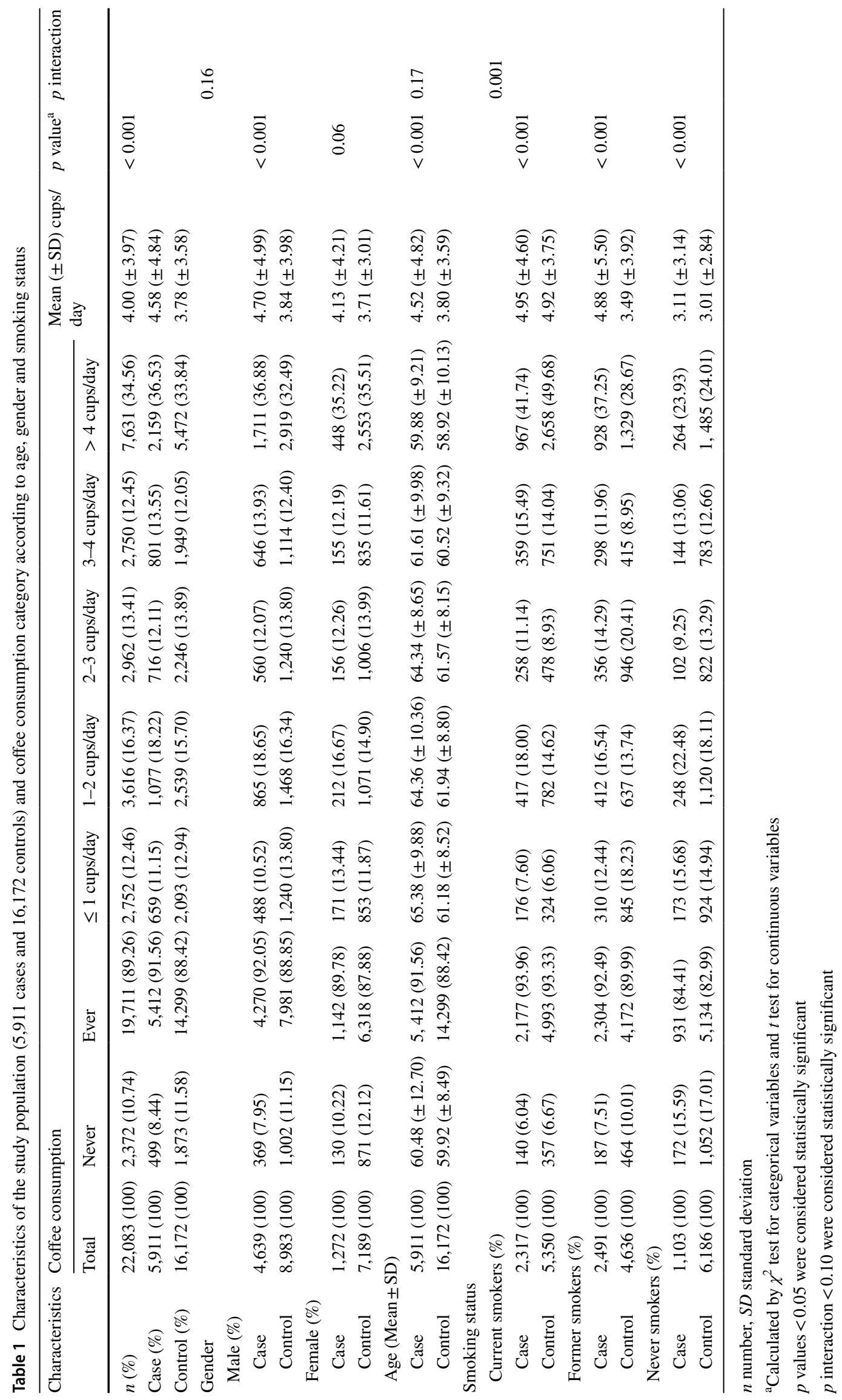


Table 2 Adjusted odds ratios and 95\% confidence intervals of bladder cancer according to coffee consumption level stratified by smoking

\begin{tabular}{|c|c|c|c|c|c|c|c|c|c|}
\hline \multirow{2}{*}{$\begin{array}{l}\text { Study sub- } \\
\text { groups }\end{array}$} & \multirow{2}{*}{$\begin{array}{l}\text { Model adjust- } \\
\text { ments }\end{array}$} & \multicolumn{7}{|c|}{ Coffee consumption (ORs and 95\% CI) } & \multirow[t]{2}{*}{$p$ trend } \\
\hline & & Never & Ever & $\leq 1 \mathrm{cups} /$ day & 1-2 cups/day & 2-3 cups/day & 3-4 cups/day & $>4$ cups/day & \\
\hline \multirow[t]{3}{*}{$\begin{array}{l}\text { Overall } \\
\qquad(n=22,083)\end{array}$} & Model $1^{\mathrm{a}}$ & Reference & $\begin{array}{l}1.42(1.26- \\
1.59)\end{array}$ & $\begin{array}{l}1.05(0.91- \\
1.22)\end{array}$ & $\begin{array}{l}1.35(1.17- \\
1.55)\end{array}$ & $\begin{array}{l}1.23(1.06- \\
1.42)\end{array}$ & $\begin{array}{l}1.51(1.31- \\
1.76)\end{array}$ & $\begin{array}{l}1.82(1.60- \\
2.07)\end{array}$ & 0.04 \\
\hline & Model $2^{\mathrm{b}}$ & Reference & $\begin{array}{l}1.11(0.98- \\
1.26)\end{array}$ & $\begin{array}{l}0.94(0.80- \\
1.10)\end{array}$ & $\begin{array}{l}1.12(0.96- \\
1.29)\end{array}$ & $\begin{array}{l}1.01(0.86- \\
1.17)\end{array}$ & $\begin{array}{l}1.16(0.99- \\
1.35)\end{array}$ & $\begin{array}{l}1.27(1.11- \\
1.46)\end{array}$ & 0.05 \\
\hline & Model $3^{c}$ & Reference & $\begin{array}{l}1.09(0.94- \\
1.25)\end{array}$ & $\begin{array}{l}0.92(0.77- \\
1.10)\end{array}$ & $\begin{array}{l}1.04(0.88- \\
1.24)\end{array}$ & $\begin{array}{l}0.97(0.81- \\
1.15)\end{array}$ & $\begin{array}{l}1.15(0.96- \\
1.37)\end{array}$ & $\begin{array}{l}1.24(1.06- \\
1.45)\end{array}$ & 0.11 \\
\hline \multirow{3}{*}{$\begin{array}{l}\text { Current light } \\
\text { smokers } \\
(n=3,548)\end{array}$} & Model $1^{\mathrm{a}}$ & Reference & $\begin{array}{l}1.01(0.68- \\
1.47)\end{array}$ & $\begin{array}{l}0.75(0.43- \\
1.30)\end{array}$ & $\begin{array}{l}0.99(0.64- \\
1.53)\end{array}$ & $\begin{array}{l}0.71(0.42- \\
1.19)\end{array}$ & $\begin{array}{l}1.31(0.84- \\
2.04)\end{array}$ & $\begin{array}{l}1.09(0.72- \\
1.63)\end{array}$ & 0.34 \\
\hline & Model $2^{\mathrm{b}}$ & Reference & $\begin{array}{l}0.97(0.65- \\
1.43)\end{array}$ & $\begin{array}{l}0.63(0.36- \\
1.11)\end{array}$ & $\begin{array}{l}0.92(0.59- \\
1.44)\end{array}$ & $\begin{array}{l}0.71(0.42- \\
1.21)\end{array}$ & $\begin{array}{l}1.24(0.79- \\
1.94)\end{array}$ & $\begin{array}{l}1.09(0.72- \\
1.66)\end{array}$ & 0.23 \\
\hline & Model $3^{\mathrm{c}}$ & Reference & $\begin{array}{l}1.16(0.71- \\
1.90)\end{array}$ & $\begin{array}{l}0.71(0.37- \\
1.35)\end{array}$ & $\begin{array}{l}1.09(0.63- \\
1.88)\end{array}$ & $\begin{array}{l}0.80(0.43- \\
1.49)\end{array}$ & $\begin{array}{l}1.46(0.85- \\
2.48)\end{array}$ & $\begin{array}{l}1.25(0.78- \\
2.07)\end{array}$ & 0.14 \\
\hline \multirow{3}{*}{$\begin{array}{l}\text { Current heavy } \\
\text { smokers } \\
(n=3,458)\end{array}$} & Model $1^{\mathrm{a}}$ & Reference & $\begin{array}{l}1.01(0.71- \\
1.41)\end{array}$ & $\begin{array}{l}0.91(0.60- \\
1.39)\end{array}$ & $\begin{array}{l}1.08(0.74- \\
1.60)\end{array}$ & $\begin{array}{l}0.92(0.63- \\
1.35)\end{array}$ & $\begin{array}{l}0.97(0.65- \\
1.44)\end{array}$ & $\begin{array}{l}1.06(0.74- \\
1.51)\end{array}$ & 0.66 \\
\hline & Model $2^{\mathrm{b}}$ & Reference & $\begin{array}{l}1.01(0.71- \\
1.42)\end{array}$ & $\begin{array}{l}0.83(0.54- \\
1.28)\end{array}$ & $\begin{array}{l}0.99(0.67- \\
1.47)\end{array}$ & $\begin{array}{l}0.91(0.62- \\
1.35)\end{array}$ & $\begin{array}{l}0.97(0.65- \\
1.46)\end{array}$ & $\begin{array}{l}1.15(0.80- \\
1.66)\end{array}$ & 0.57 \\
\hline & Model $3^{\mathrm{c}}$ & Reference & $\begin{array}{l}0.92(0.59- \\
1.41)\end{array}$ & $\begin{array}{l}0.75(0.45- \\
1.24)\end{array}$ & $\begin{array}{l}0.78(0.48- \\
1.29)\end{array}$ & $\begin{array}{l}0.82(0.51- \\
1.32)\end{array}$ & $\begin{array}{l}0.89(0.55- \\
1.45)\end{array}$ & $\begin{array}{l}1.03(0.66- \\
1.61)\end{array}$ & 0.34 \\
\hline \multirow{3}{*}{$\begin{array}{l}\text { Former light } \\
\text { smokers } \\
\quad(n=3,314)\end{array}$} & Model $1^{\mathrm{a}}$ & Reference & $\begin{array}{l}1.24(0.91- \\
1.70)\end{array}$ & $\begin{array}{l}1.03(0.71- \\
1.51)\end{array}$ & $\begin{array}{l}1.20(0.82- \\
1.76)\end{array}$ & $\begin{array}{l}1.36(0.95- \\
1.97)\end{array}$ & $\begin{array}{l}1.37(0.90- \\
2.08)\end{array}$ & $\begin{array}{l}1.29(0.91- \\
1.83)\end{array}$ & 0.07 \\
\hline & Model $2^{\mathrm{b}}$ & Reference & $\begin{array}{l}1.28(0.93- \\
1.75)\end{array}$ & $\begin{array}{l}1.01(0.68- \\
1.48)\end{array}$ & $\begin{array}{l}1.19(0.81- \\
1.75)\end{array}$ & $\begin{array}{l}1.44(0.99- \\
2.09)\end{array}$ & $\begin{array}{l}1.36(0.89- \\
2.08)\end{array}$ & $\begin{array}{l}1.41(0.99- \\
2.02)\end{array}$ & 0.06 \\
\hline & Model $3^{\mathrm{c}}$ & Reference & $\begin{array}{l}1.30(0.90- \\
1.88)\end{array}$ & $\begin{array}{l}1.05(0.68- \\
1.62)\end{array}$ & $\begin{array}{l}1.14(0.74- \\
1.77)\end{array}$ & $\begin{array}{l}1.50(0.99- \\
2.27)\end{array}$ & $\begin{array}{l}1.39(0.87- \\
2.21)\end{array}$ & $\begin{array}{l}1.38(0.93- \\
2.07)\end{array}$ & 0.09 \\
\hline \multirow{3}{*}{$\begin{array}{l}\text { Former heavy } \\
\text { smokers } \\
(n=3,202)\end{array}$} & Model $1^{\mathrm{a}}$ & Reference & $\begin{array}{l}1.02(0.76- \\
1.37)\end{array}$ & $\begin{array}{l}0.83(0.58- \\
1.17)\end{array}$ & $\begin{array}{l}0.96(0.67- \\
1.37)\end{array}$ & $\begin{array}{l}0.90(0.64- \\
1.26)\end{array}$ & $\begin{array}{l}1.03(0.71- \\
1.49)\end{array}$ & $\begin{array}{l}1.28(0.93- \\
1.76)\end{array}$ & 0.19 \\
\hline & Model $2^{b}$ & Reference & $\begin{array}{l}1.01(0.75- \\
1.35)\end{array}$ & $\begin{array}{l}0.80(0.57- \\
1.13)\end{array}$ & $\begin{array}{l}0.93(0.65- \\
1.33)\end{array}$ & $\begin{array}{l}0.89(0.63- \\
1.24)\end{array}$ & $\begin{array}{l}1.03(0.71- \\
1.49)\end{array}$ & $\begin{array}{l}1.28(0.93- \\
1.76)\end{array}$ & 0.18 \\
\hline & Model $3^{\mathrm{c}}$ & Reference & $\begin{array}{l}0.92(0.66- \\
1.27)\end{array}$ & $\begin{array}{l}0.72(0.49- \\
1.05)\end{array}$ & $\begin{array}{l}0.79(0.53- \\
1.18)\end{array}$ & $\begin{array}{l}0.78(0.54- \\
1.13)\end{array}$ & $\begin{array}{l}0.96(0.64- \\
1.44)\end{array}$ & $\begin{array}{l}1.20(0.85- \\
1.70)\end{array}$ & 0.07 \\
\hline \multirow{3}{*}{$\begin{array}{l}\text { Never } \\
\text { smokers } \\
\quad(n=7,289)\end{array}$} & Model $1^{\mathrm{a}}$ & Reference & $\begin{array}{l}1.36(1.12- \\
1.67)\end{array}$ & $\begin{array}{l}1.31(1.01- \\
1.70)\end{array}$ & $\begin{array}{l}1.53(1.20- \\
1.96)\end{array}$ & $\begin{array}{l}1.04(0.78- \\
1.39)\end{array}$ & $\begin{array}{l}1.31(0.99- \\
1.74)\end{array}$ & $\begin{array}{l}1.52(1.19- \\
1.94)\end{array}$ & 0.23 \\
\hline & Model $2^{\mathrm{b}}$ & Reference & $\begin{array}{l}1.30(1.06- \\
1.59)\end{array}$ & $\begin{array}{l}1.18(0.90- \\
1.55)\end{array}$ & $\begin{array}{l}1.36(1.05- \\
1.76)\end{array}$ & $\begin{array}{l}0.96(0.71- \\
1.30)\end{array}$ & $\begin{array}{l}1.22(0.91- \\
1.64)\end{array}$ & $\begin{array}{l}1.52(1.18- \\
1.97)\end{array}$ & 0.23 \\
\hline & Model $3^{\mathrm{c}}$ & Reference & $\begin{array}{l}1.31(1.03- \\
1.66)\end{array}$ & $\begin{array}{l}1.28(0.95- \\
1.73)\end{array}$ & $\begin{array}{l}1.42(1.06- \\
1.89)\end{array}$ & $\begin{array}{l}0.97(0.70- \\
1.34)\end{array}$ & $\begin{array}{l}1.24(0.91- \\
1.70)\end{array}$ & $\begin{array}{l}1.51(1.15- \\
1.99)\end{array}$ & 0.24 \\
\hline
\end{tabular}

Referent group was never coffee consumers

$O R$ odds ratio, $C I$ confidence interval

${ }^{a}$ Model 1: Crude model

${ }^{\mathrm{b}}$ Model 2: Adjusted for age, gender and smoking (in the overall analyses)

${ }^{\mathrm{c}}$ Model 3: Additionally adjusted for water, liquid milk, alcohol, carbonated drinks, tea and juice

$p$ trend $<0.05$ were considered statistically significant

when comparing high ( $>4$ cups/day) coffee consumption to never coffee consumers $\left(\mathrm{OR}_{\text {model } 2} 1.52,95 \%\right.$ CI 1.19-1.94, $p$ trend $=0.23$ ). Among smokers no significant association could be observed; however, former light smokers showed again slightly higher and borderline significant results compared to other type of smokers $\left(\mathrm{OR}_{\text {model } 2} 1.41,95 \% \mathrm{CI}\right.$ $0.99-2.02, p$ trend=0.06). The coffee cup size standardized analysis also showed significantly increased BC risk estimates with more than four cups/day coffee consumption (Supplementary Table 3).

Results for the comparison of caffeinated and decaffeinated coffee are shown in Supplementary Tables 1 and 2. For the analysis on caffeinated coffee consumption, only 1 (France-1) out of the 13 included case-control studies could be included (including 187 cases/296 controls). For the analysis on decaffeinated coffee, two studies (Italy-1 and USA-4) 


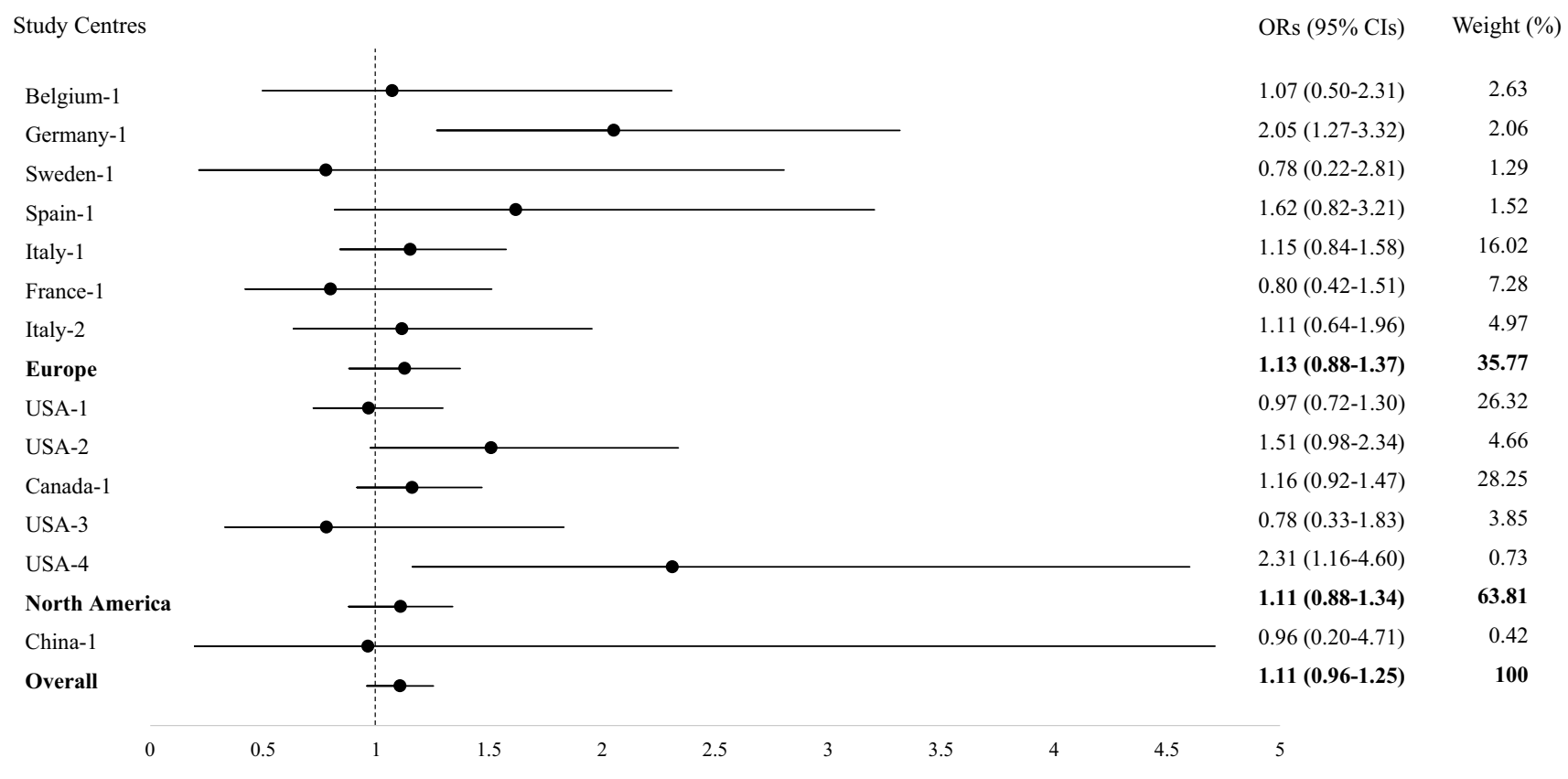

Fig. 1 Forest Plot of Meta-Analysis with ORs and 95\% CIs for Ever and Never Coffee Consumption with Bladder Cancer Risk Adjusted for Age, Gender and Smoking by Geographical Regions. OR odds ratio, CI confidence interval. Circle dots denote the odds ratios

had sufficient data to be included in our analyses (including 1,048 cases/1,487 controls). Consumers of caffeinated coffee showed significant increased risks (compared to decaffeinated coffee consumers: $\mathrm{OR}_{\text {model } 2} 1.88,95 \%$ CI $1.42-2.48$; compared to never coffee consumers: $\mathrm{OR}_{\text {model } 2} 1.52,95 \%$ CI 1.06-2.21), whereas, decaffeinated coffee consumers showed a null association with BC compared to never coffee consumers.

\section{Dose-response analyses}

Dose-response relationships between coffee consumption and the risk of $\mathrm{BC}$ are displayed in Fig. 2. The tests for nonlinearity were not statistically significant; hence, linear models were applied in the dose-response analyses. The curves for the overall population showed a slightly increased $\mathrm{BC}$ risks with the increment of coffee consumption. Similar results were found among ever and never smokers; however, among never smokers the increased BC risk was significant for consuming over four cups/day, while for ever smokers for consumption over six cups/day. Adjusted ORs and 95\% CIs for one cup/day increment were 1.14 (95\% CI 1.05-1.24) in overall study population, 1.05 (95\% CI $1.02-1.15)$ in ever smokers, 1.16 (95\% CI 1.04-1.41) in never smokers. In addition, both curves for hospital-based studies and populationbased studies showed increased BC risks with the increment of cups of coffee consumption per day. However, in hospital-based studies a statistically significant increase BC risk
(ORs); Horizontal lines represent the 95\% confidence intervals (CIs); Weights are from random-effect model. Europe pooled OR of studies from Europe; North America pooled OR of studies from North America; Overall pooled OR of all studies

was observed for consuming over two cups/day, while for population-based studies a significant increase was observed for consuming over five cups/day (Supplementary Fig. 2).

\section{Population-attributable risks}

Assuming an incidence of heavy coffee drinking of $28 \%$ and $17 \%$, in Europe and North America respectively, a PAR of $7.94 \%$ for Europe and $4.45 \%$ for North America was observed.

\section{Discussion}

This large multi centric study found an overall increased risk of $\mathrm{BC}$ with high ( $>4$ cups/day) coffee consumption. In addition, we showed that this increased risk was only observed among never smokers, but not found among smokers.

The interaction between coffee and smoking has already been studied with some detail, and experimental studies showed that smokers eliminate caffeine faster, suggesting that the effect of coffee consumption on BC risk is lower among smokers $[33,55]$. In fact, faster metabolism of caffeine in smokers would allow them to consume higher levels before experiencing symptoms of caffeine toxicity [56-58]. Moreover, this hypothesis is strengthened by experimental studies reporting that the cytochrome P450 1A2 (CYP1A2) metabolic pathway is upregulated by both caffeine and 

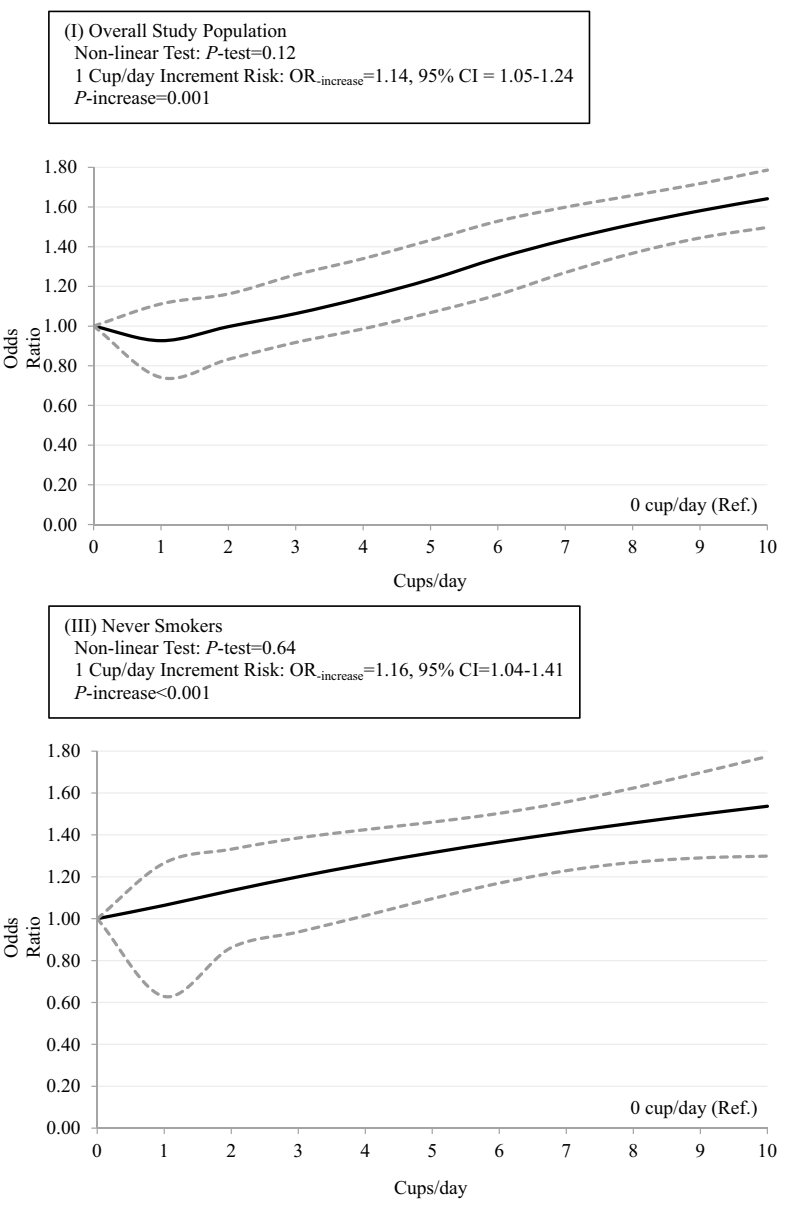

Fig. 2 Dose-response Relationships between Coffee Consumption and the Risk of Bladder Cancer among I) Overall study population; II) Ever Smokers; III) Never Smokers. The solid lines represent the odds ratios (ORs). The dashed lines represent the 95\% confidence intervals (CIs) for the trend. The ORs were adjusted for age, gender

compounds in tobacco smoke, including nicotine and polycyclic aromatic hydrocarbons (PAHs) [59-61], so that the effect of caffeine is potentially weaker among smokers than among never smokers. These experimental studies are in line with our result showing an increased BC risk among never smokers only. Several epidemiological studies (both case-control and cohort) also suggested a higher $\mathrm{BC}$ risks for coffee consumers among never smokers only or a null association among smokers [40, 62-66]. A meta-analysis of epidemiological studies also suggested that the increased BC risk of coffee consumption was higher among never smokers than among smokers [31]. However, a more recent prospective cohort study (2017) [67] conducted in the United States, which showed that high coffee consumption ( $>4$ cups/day) was positively associated with $\mathrm{BC}$ risk, could not observe an increased $\mathrm{BC}$ risk among never smokers only. This discrepancy may be due to the limited number of cases in their smoking-stratified analysis.

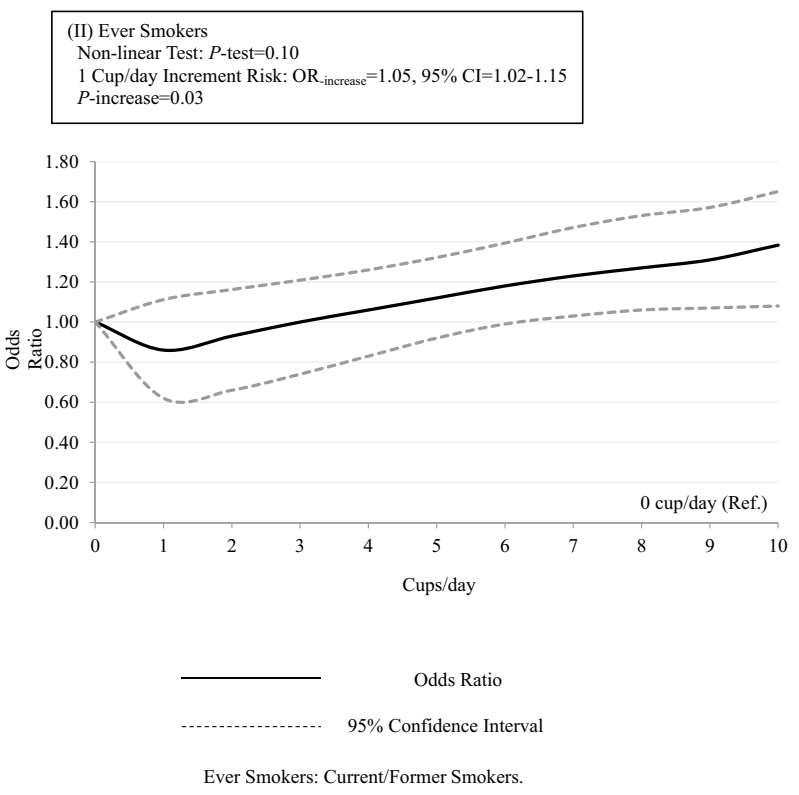

Abbreviation: $\mathrm{OR}=$ Odds Ratio; $\mathrm{CI}=$ Confidence Interval.

$P$-test $<0.05$ were considered statistically significant; $P$-increase $<0.05$ were considered statistically significant.

and smoking (in the overall study population) (model 2). OR odds ratio; $C I$ confidence interval. $P$ test $<0.05$ were considered statistically significant; $p$ increase $<0.05$ were considered statistically significant

Coffee contains high content of caffeine, which has shown mutagenic effects in human cells [68], a proven influence on suppressing the activation of the protein kinase ataxia-telangiectasia mutated (ATM) and the phosphorylation of the kinase Chk2, both important for the activation of the tumor suppressor gene P53 [69, 70]. It could, therefore, be suggested that the increased BC risk is due to the caffeine content of coffee. Previous epidemiological studies already confirmed this hypothesis by showing a null association between $\mathrm{BC}$ risk and decaffeinated coffee [71] and an increased BC risk for caffeinated coffee $[72,73]$. The present study also showed an increased BC risk when comparing caffeinated coffee consumers versus decaffeinated coffee consumers. However, due to lack of data, we were unable to perform further analyses, i.e., the association between the intensity of caffeinated coffee consumption and BC.

Besides caffeine, coffee also included other compounds, such as several phenolic compounds (i.e., chlorogenic, 
caffeic acid, ferulic, and coumaric acids), melanoidins, and diterpenes (i.e., cafestol and kahweol), with anti-carcinogenic properties [74-80]. This might explain why the consumption of less than four coffee cups/day showed a null association with $\mathrm{BC}$ risk. In addition, experimental research on the mechanisms of action of coffee compounds on P53 suppression showed this effect to be concentration dependent [69, 81-84].

The present study found a four cups/day threshold for an increased BC risk in both the overall study population and among never smokers. This finding is in line with previous reported meta-analyses based on case-control studies, also showing an increased BC risk over four cups/day (respectively OR 1.29, 95\% CI 1.12-1.48; OR 1.20, 95\% CI 1.12-1.24) [31, 85]. Among smokers, however, a threshold of six cups/day was observed; this again shows that the effect of coffee on BC risk might be influenced by the faster caffeine metabolism among smokers.

An issue that may arise in evaluating the influence of coffee consumption on BC risk in hospital-based case-control studies is that the controls includes patients suffering from a disease that may influence coffee intake (i.e., heart issues), resulting in inflated ORs. In the present study, therefore, stratified analyses by study design (i.e., hospital-based controls or population-based controls) were performed, and the association with coffee consumption was higher, though not significantly, in hospital-based studies than it was in population-based studies, where similar results were found in both ever versus never coffee consumption and dose-response analyses (Supplementary Figs. 1 and 2).

For the present study, the estimates of PAR showed that in Europe $7.94 \%$ and in North America $4.45 \%$ of incidence of $\mathrm{BC}$ cases could be attributed to heavy coffee consumption (i.e., $>4$ cups/day). Unfortunately, the exact prevalence of heavy coffee drinking in the Eastern Asian population is yet unknown. However, since anecdotal evidence suggests that coffee consuming is on the rise in Eastern Asia, the PAR is expected to increase Eastern Asian countries over the next years.

Among the strengths of the BLEND study there is the large sample size, allowing to perform detailed analyses with enough statistical power to detect smaller effects, the study has also some limitations. First, it is known that the size of standard coffee cups is varied around the world, and the effect of a cup of coffee on BC might, therefore, differ between different countries. However, our per-center analyses as well our standardized analysis, in which we transformed a United States (U.S.) cup size to a $237 \mathrm{ml}$ coffee cup size according to U.S. Food and Drug Administration [51] and an Asian cup size to a $500 \mathrm{ml}$ cup size according to the questionnaire used in the study of Lu et al. [45], showed similar results (Supplementary Table 3: $\mathrm{OR}_{\text {model2 }} 1.25,95 \%$ CI $1.06-1.47, p$ trend $=0.18$ ). Due to large heterogeneity among coffee cup size among European countries, Europe was not included in these standardized analyses. In addition, it is suggested that the strength of coffee brew may compensate for the different serving size between countries [86].

Second, it is often suggested that case-control studies are limited in showing causal relation, due to the potential recall bias of case-control studies. This might have led to a lower reliability of the results compared to those of cohort studies. However, although this issue has been addressed and analyzed for its consequences in many epidemiologi$\mathrm{cal} /$ methodological papers [87-90], no clear answer on the magnitude of the effect of this specific type of bias could be draw.

Thirdly, limited information was available on possible risk factors, other than age, gender and smoking, for the development of BC, such as body mass index (BMI), physical activity, socioeconomic status (SES), disinfection byproducts, arsenic in the drinking water, and occupational exposures to potentially carcinogenic chemicals. Although, adjustments for these factors could have influenced the results, current literature shows that only a small proportion of $\mathrm{BC}$ cases can be attributed to these factors [72]. Last, although status as well as duration and intensity of smoking were taken into account in our analysis, the adjustment for smoking might still be imperfect due to differences in smoking practices (e.g., depth of inhalation or amount of inhalation), or differences in types of smoke exposure [67]. In addition, since smoking is perceived as a socially undesirable behavior, the use of self-reported questionnaires for smoking status, duration, and intensity might have led to underreporting of the actual smoking habits.

\section{Conclusion}

In summary, the present study, with more than 5,900 cases, observed an increased risk between high ( $>4$ cups/day) coffee consumption and $\mathrm{BC}$ among never smokers, while no association with $\mathrm{BC}$ risk was observed with coffee consumption among smokers. Additionally, it indicates that around 7.94\% of BC cases for Europe and $4.45 \%$ of BC cases for North America in the population might be attributable to heavy coffee consumption ( $>4$ cups/day).

Acknowledgments We gratefully acknowledge all principal investigators for their willingness to participate in this jointed project. The author E Y.W. YU gives thanks to the financial support from China Scholarship Council (No. 201706310135).

Author contributions Study conception and design: AW and MPZ; Analyses and interpretation of data: EYY and FVO; Drafting of the manuscript: EYY; Revised the manuscript: AW, FVO, and MPZ; Provided the data: MCS, XJ, EK, CML, HP, GS, JM, MFA, CLV, KCJ, $\mathrm{SB}, \mathrm{ZFZ}, \mathrm{CB}$, JAT, and MPZ; Approved the manuscript: all authors. 
Funding This work was partly funded by the Word Cancer Research Fund International (WCRF 2012/590) and European Commission. The Hessen Case-control study on bladder cancer was supported by the Bundesanstalt für Arbeitsschutz (No. F 1287). The Kaohsiung study was supported by grant NSC 85-2332-B-037-066 from the National Scientific Council of the Republic of China. The Stockholm Casecontrol study was supported by grant from the Swedish National Cancer Society and from the Swedish Work Environment Fund. The New England bladder cancer study was funded in part by Grant Nos. 5 P42 ES007373 from the National Institute of Environmental Health Sciences, NIH and CA57494 from the National Cancer Institute, NIH. The Italian Case-control study on bladder cancer was conducted within the framework of the CNR (Italian National Research Council) Applied Project "Clinical Application of Oncological Research" (contracts: 94.01321.PF39 and 94.01119.PF39), and with the contributions of the Italian Association for Cancer Research, the Italian League against Tumours, Milan, and Mrs. Angela Marchegiano Borgomainerio. The Brescia bladder cancer study was partly supported by the International Agency for Research on Cancer. The French INSERM study was supported by a grant from the Direction Générale de la Santé, Ministère des Affaires Sociales, France. The Molecular Epidemiology of Bladder Cancer and Prostate Cancer was supported in part by grants ES06718 (to Z.-F.Z.), U01 CA96116 (to A.B.), and CA09142 from the NIH National Institute of Environmental Health Sciences, the National Cancer Institute, the Department of Health and Human Services, and by the Ann Fitzpatrick Alper Program in Environmental Genomics at the Jonsson Comprehensive Cancer Centre, UCLA.

\section{Compliance with ethical standards}

Conflict of interest All the authors declare that they have no conflicts of interest.

Ethics approval Each participating study has been approved by the local ethic committee.

Open Access This article is distributed under the terms of the Creative Commons Attribution 4.0 International License (http://creativeco mmons.org/licenses/by/4.0/), which permits unrestricted use, distribution, and reproduction in any medium, provided you give appropriate credit to the original author(s) and the source, provide a link to the Creative Commons license, and indicate if changes were made.

\section{References}

1. Ferlay J, Soerjomataram I, Dikshit R et al (2015) Cancer incidence and mortality worldwide: sources, methods and major patterns in GLOBOCAN 2012. Int J Cancer 136(5):E359-E386

2. Siegel RL, Miller KD, Jemal A (2017) Cancer statistics, 2017. CA Cancer J Clin 67(1):7-30

3. Antoni S, Ferlay J, Soerjomataram I et al (2017) Bladder cancer incidence and mortality: a global overview and recent trends. Eur Urol 71(1):96-108

4. Jemal A, Bray F, Center MM et al (2011) Global cancer statistics. CA Cancer J Clin 61(2):69-90

5. Ploeg M, Aben KK, Kiemeney LA (2009) The present and future burden of urinary bladder cancer in the world. World J Urol 27(3):289-293

6. Marugame T, Mizuno S (2005) Comparison of prostate cancer mortality in five countries: France, Italy, Japan, UK and USA from the WHO mortality database (1960-2000). Jpn J Clin Oncol 35(11):690-691

7. Stewart B, Wild CP (2017) World cancer report 2014. International Agency for Research on Cancer, World Health Organization. WHO Press, Geneva

8. Letašiová S, Medved’ová A, Šovčíková A et al (2012) Bladder cancer, a review of the environmental risk factors. Environ Health 11(Suppl 1):S11

9. Botteman MF, Pashos CL, Redaelli A, Laskin B, Hauser R (2003) The health economics of bladder cancer. Pharmacoeconomics 21(18):1315-1330

10. Johansson SL, Cohen SM (1997) Epidemiology and etiology of bladder cancer. In: Seminars in surgical oncology. Wiley, New York

11. Cole P (1971) Coffee-drinking and cancer of the lower urinary tract. Lancet 1(7713):1335-1337

12. IARC Working Group on the Evaluation of Carcinogenic Risks to Humans (1991) Coffee, tea, mate, methylxanthines and methylglyoxal: World Health Organization. International Agency for Research on Cancer, vol 51

13. Pannelli F, La Rosa F, Saltalamacchia G et al (1989) Tobacco smoking, coffee, cocoa and tea consumption in relation to mortality from urinary bladder cancer in Italy. Eur J Epidemiol 5(3):392-397

14. Risch HA, Burch JD, Miller AB et al (1988) Dietary factors and the incidence of cancer of the urinary bladder. Am J Epidemiol 127(6):1179-1191

15. Ciccone G, Vineis $P$ (1988) Coffee drinking and bladder cancer. Cancer Lett 41(1):45-52

16. Jensen OM, Wahrendorf J, Knudsen JB, Sorensen BL (1986) The Copenhagen case-control study of bladder cancer. II. Effect of coffee and other beverages. Int J Cancer 37(5):651-657

17. Bravo P, del Rey J, Sanchez J, Conde M (1986) Coffee and analgesics as risk factors for cancer of the bladder. Arch Esp Urol 39(5):337-341

18. Rebelakos A, Trichopoulos D, Tzonou A et al (1985) Tobacco smoking, coffee drinking, and occupation as risk factors for bladder cancer in Greece. J Natl Cancer Inst 75(3):455-461

19. Gonzalez CA, Lopez-Abente G, Errezola M et al (1985) Occupation, tobacco use, coffee, and bladder cancer in the county of Mataro (Spain). Cancer 55(9):2031-2034

20. Hopkins J (1984) Coffee drinking and bladder cancer. Food Chem Toxicol 22(6):481-483

21. Marrett LD, Walter SD, Meigs JW (1983) Coffee drinking and bladder cancer in Connecticut. Am J Epidemiol 117(2):113-127

22. Hartge P, Hoover R, West DW, Lyon JL (1983) Coffee drinking and risk of bladder cancer. J Natl Cancer Inst 70(6):1021-1026

23. Howe GR, Burch JD, Miller AB et al (1980) Tobacco use, occupation, coffee, various nutrients, and bladder cancer. J Natl Cancer Inst 64(4):701-713

24. Abou-Daoud KT (1980) Cancer of the bladder and cigarette smoking, coffee and alcohol drinking in Lebanon. J Med Liban 31(3):251-257

25. Bross ID, Tidings J (1973) Another look at coffee drinking and cancer of the urinary bladder. Prev Med 2(3):445-451

26. Zeitlin BR (1972) Coffee and bladder cancer. Lancet 1(7759):1066

27. Fraumeni JF Jr, Scotto J, Dunham LJ (1971) Coffee-drinking and bladder cancer. Lancet 2(7735):1204

28. Loomis D, Guyton KZ, Grosse Y et al (2016) Carcinogenicity of drinking coffee, mate, and very hot beverages. Lancet Oncol 17(7):877-878

29. Johan HB, Nordestgaard AT, Taylor AE et al (2017) Heavier smoking increases coffee consumption: findings from a Mendelian randomization analysis. Int J Epidemiol 46(6):1958-1967 
30. Swanson JA, Lee JW, Hopp JW (1994) Caffeine and nicotine: a review of their joint use and possible interactive effects in tobacco withdrawal. Addict Behav 19(3):229-256

31. Zhou Y, Tian C, Jia C (2012) A dose-response meta-analysis of coffee consumption and bladder cancer. Prev Med 55(1):14-22

32. Benowitz NL, Peng M, Jacob P (2003) Effects of cigarette smoking and carbon monoxide on chlorzoxazone and caffeine metabolism. Clin Pharmacol Ther 74(5):468-474

33. Zevin S, Benowitz NL (1999) Drug interactions with tobacco smoking. Clin Pharmacokinet 36(6):425-438

34. De Leon J, Diaz FJ, Rogers T et al (2003) A pilot study of plasma caffeine concentrations in a US sample of smoker and nonsmoker volunteers. Prog Neuropsychopharmacol Biol Psychiatry 27(1):165-171

35. Plowchalk DR, Yeo KR (2012) Prediction of drug clearance in a smoking population: modeling the impact of variable cigarette consumption on the induction of CYP1A2. Eur J Clin Pharmacol 68(6):951-960

36. Goossens ME, Isa F, Brinkman M et al (2016) International pooled study on diet and bladder cancer: the bladder cancer, epidemiology and nutritional determinants (BLEND) study: design and baseline characteristics. Arch Public Health 74(1):30-39

37. Pohlabeln H, Jockel KH, Bolm-Audorff U (1999) Non-occupational risk factors for cancer of the lower urinary tract in Germany. Eur J Epidemiol 15(5):411-419

38. Mettlin C, Graham S (1979) Dietary risk factors in human bladder cancer. Am J Epidemiol 110(3):255-263

39. Johnson K, Mao Y, Argo J et al (1998) The National Enhanced Cancer Surveillance System: a case-control approach to environment-related cancer surveillance in Canada. Environmetrics 9(5):495-504

40. Clavel J, Cordier S (1991) Coffee consumption and bladder cancer risk. Int J Cancer 47(2):207-212

41. Cao W, Cai L, Rao JY et al (2005) Tobacco smoking, GSTP1 polymorphism, and bladder carcinoma. Cancer 104(11):2400-2408

42. Taylor JA, Umbach DM, Stephens E et al (1998) The role of $\mathrm{N}$-acetylation polymorphisms in smoking-associated bladder cancer: evidence of a gene-gene-exposure three-way interaction. Cancer Res 58(16):3603-3610

43. Jiang X, Castelao JE, Groshen S et al (2007) Alcohol consumption and risk of bladder cancer in Los Angeles County. Int J Cancer 121(4):839-845

44. Kellen E, Zeegers M, Paulussen A, Van Dongen M, Buntinx F (2006) Fruit consumption reduces the effect of smoking on bladder cancer risk. The Belgian case control study on bladder cancer. Int J Cancer 118(10):2572-2578

45. Lu CM, Lan SJ, Lee YH et al (1999) Tea consumption: fluid intake and bladder cancer risk in Southern Taiwan. Urology. 54(5):823-828

46. Steineck G, Hagman U, Gerhardsson M, Norell SE (1990) Vitamin A supplements, fried foods, fat and urothelial cancer A case-referent study in Stockholm in 1985-87. Int J Cancer 45(6):1006-1011

47. Baena AV, Allam MF, Del Castillo AS et al (2006) Urinary bladder cancer risk factors in men: a Spanish case-control study. Eur J Cancer Prev 15(6):498-503

48. Shen M, Hung RJ, Brennan P et al (2003) Polymorphisms of the DNA repair genes XRCC1, XRCC3, XPD, interaction with environmental exposures, and bladder cancer risk in a case-control study in northern Italy. Cancer Epidemiol Biomark Prev 12(11 Pt 1):1234-1240

49. D’Avanzo B, La Vecchia C, Negri E, Decarli A, Benichou J (1995) Attributable risks for bladder cancer in northern Italy. Ann Epidemiol 5(6):427-431
50. Poortvliet E, Klensin J, Kohlmeier L (1992) Rationale document for the Eurocode 2 food coding system (version 91/2). Eur J Clin Nutr 46(Suppl 5):S9-S24

51. US Food Drug Administration (2012) Guidance for industry: drug interaction studies-study design, data analysis, implications for dosing, and labeling recommendations. US Food and Drug Administration, Rockville, pp 1-75

52. Royston P, Altman DG (1997) Approximating statistical functions by using fractional polynomial regression. J R Stat Soc 46(3):411-422

53. Jones BL, Nagin DS (2012) A Stata plugin for estimating groupbased trajectory models. Sociol Methods Res 42(4):608-613

54. Bagnardi V, Zambon A, Quatto P, Corrao G (2004) Flexible metaregression functions for modeling aggregate dose-response data, with an application to alcohol and mortality. Am J Epidemiol 159(11):1077-1086

55. Mihi YTK, Takahiko K, Koji M (1998) Effects of lifestyle and genetic polymorphisms on consumption of coffee or black tea and urinary caffeine levels. Biomarkers 3(4-5):367-377

56. Joeres R, Klinker H, Heusler $H$ et al (1988) Influence of smoking on caffeine elimination in healthy volunteers and in patients with alcoholic liver cirrhosis. Hepatology 8(3):575-579

57. Langmann $P$, Bienert A, Zilly M et al (2000) Influence of smoking on cotinine and caffeine plasma levels in patients with alcoholic liver cirrhosis. Eur J Med Res 5(5):217-221

58. Ossip DJ, Epstein LH (1981) Relative effects of nicotine and coffee on cigarette smoking. Addict Behav 6(1):35-39

59. Landi M, Sinha R, Lang N, Kadlubar F (1999) Human cytochrome P4501A2. IARC Sci Publ 148:173-195

60. Kalow W, Tang BK (1991) Use of caffeine metabolite ratios to explore CYP1A2 and xanthine oxidase activities. Clin Pharmacol Ther 50(5-1):508-519

61. Gunes A, Dahl M-L (2008) Variation in CYP1A2 activity and its clinical implications: influence of environmental factors and genetic polymorphisms. Pharmacogenomics 9(5):625-637

62. Donato F, Boffetta P, Fazioli R et al (1997) Bladder cancer, tobacco smoking, coffee and alcohol drinking in Brescia, northern Italy. Eur J Epidemiol 13(7):795-800

63. Vena JE, Freudenheim JO, Graham S et al (1993) Coffee, cigarette smoking, and bladder cancer in western New York. Ann Epidemiol 3(6):586-591

64. Escolar Pujolar A, Gonzalez CA, Lopez-Abente G et al (1993) Bladder cancer and coffee consumption in smokers and nonsmokers in Spain. Int J Epidemiol 22(1):38-44

65. D’Avanzo B, La Vecchia C, Franceschi S et al (1992) Coffee consumption and bladder cancer risk. Eur J Cancer 28(8-9):1480-1484

66. Hashemian M, Sinha R, Murphy G et al (2019) Cofee and tea drinking and risk of cancer of the urinary tract in male smokers. Ann Epidemiol. https://doi.org/10.1016/j.annepidem.2019.03.014

67. Loftfield E, Freedman ND, Inoue-Choi M, Graubard BI, Sinha $\mathrm{R}$ (2017) A prospective investigation of coffee drinking and bladder cancer incidence in the United States. Epidemiology 28(5):685-693

68. Kuhlmann W, Fromme H-G, Heege E-M, Ostertag W (1968) The mutagenic action of caffeine in higher organisms. Cancer Res 28(11):2375-2389

69. Zhang Z-W, Xiao J, Luo W, Wang B-H, Chen J-M (2015) Caffeine suppresses apoptosis of bladder cancer RT4 cells in response to ionizing radiation by inhibiting ataxia telangiectasia mutatedChk2-p53 axis. Chin Med J 128(21):2938-2945

70. Sarkaria JN, Busby EC, Tibbetts RS et al (1999) Inhibition of ATM and ATR kinase activities by the radiosensitizing agent, caffeine. Cancer Res 59(17):4375-4382 
71. Turati F, Bosetti C, Polesel J et al (2015) Coffee, tea, cola, and bladder cancer risk: dose and time relationships. Urology 86(6):1179-1184

72. Sugiyama K, Sugawara Y, Tomata Y, Nishino Y, Fukao A, Tsuji I (2017) The association between coffee consumption and bladder cancer incidence in a pooled analysis of the Miyagi Cohort Study and Ohsaki Cohort Study. Eur J Cancer Prev 26(2):125-130

73. Slattery ML, West DW, Robison LM (1988) Fluid intake and bladder cancer in Utah. Int J Cancer 42(1):17-22

74. Cavin C, Holzhaeuser D, Scharf G et al (2002) Cafestol and kahweol, two coffee specific diterpenes with anticarcinogenic activity. Food Chem Toxicol 40(8):1155-1163

75. Huber WW, Scharf G, Nagel G et al (2003) Coffee and its chemopreventive components Kahweol and Cafestol increase the activity of $\mathrm{O}$ 6-methylguanine-DNA methyltransferase in rat livercomparison with phase II xenobiotic metabolism. Mutat Res 522(1):57-68

76. Bravi F, Bosetti C, Tavani A et al (2007) Coffee drinking and hepatocellular carcinoma risk: a meta-analysis. Hepatology 46(2):430-435

77. Bravi F, Scotti L, Bosetti C et al (2009) Coffee drinking and endometrial cancer risk: a metaanalysis of observational studies. Am J Obstet Gynecol 200(2):130-135

78. Je Y, Liu W, Giovannucci E (2009) Coffee consumption and risk of colorectal cancer: a systematic review and meta-analysis of prospective cohort studies. Int J Cancer 124(7):1662-1668

79. Galeone C, Tavani A, Pelucchi C et al (2010) Coffee and tea intake and risk of head and neck cancer: pooled analysis in the international head and neck cancer epidemiology consortium. Cancer Epidemiol Biomark Prev 19(7):1723-1736

80. Turati F, Galeone C, La Vecchia C, Garavello W, Tavani A (2010) Coffee and cancers of the upper digestive and respiratory tracts: meta-analyses of observational studies. Ann Oncol 22(3):536-544

81. Ames BN, Gold LS (1997) The causes and prevention of cancer: gaining perspective. Environ Health Perspect 105(Suppl 4):865-873
82. Asaad NA, Zeng Z-C, Guan J, Thacker J, Iliakis G (2000) Homologous recombination as a potential target for caffeine radiosensitization in mammalian cells: reduced caffeine radiosensitization in XRCC2 and XRCC3 mutants. Oncogene 19(50):5788-5800

83. Saiki S, Sasazawa Y, Imamichi Y et al (2011) Caffeine induces apoptosis by enhancement of autophagy via PI3 K/Akt/mTOR/ p70S6 K inhibition. Autophagy 7(2):176-187

84. Cortez D (2003) Caffeine inhibits checkpoint responses without inhibiting the ataxia-telangiectasia-mutated (ATM) and ATM-and Rad3-related (ATR) protein kinases. J Biol Chem 278(39):37139-37145

85. Wu W, Tong Y, Zhao Q et al (2015) Coffee consumption and bladder cancer: a meta-analysis of observational studies. Sci Rep 5:1-9

86. Bracken MB, Triche E, Grosso L et al (2002) Heterogeneity in assessing self-reports of caffeine exposure: implications for studies of health effects. Epidemiology 13(2):165-171

87. Barry D (1996) Differential recall bias and spurious associations in case/control studies. Stat Med 15(23):2603-2616

88. Barry D, Livingstone V (2006) The investigation and correction of recall bias for an ordinal response in a case-control study. Stat Med 25(6):965-975

89. Chouinard E, Walter S (1995) Recall bias in case-control studies: an empirical analysis and theoretical framework. J Clin Epidemiol 48(2):245-254

90. Gefeller O (2009) Invited commentary: recall bias in melanomamuch ado about almost nothing? Am J Epidemiol 169(3):267-270 discussion 71-2

Publisher's Note Springer Nature remains neutral with regard to jurisdictional claims in published maps and institutional affiliations.

\section{Affiliations}

\section{Evan Yi-Wen $\mathrm{Yu}^{1,2} \oplus$ - Anke Wesselius ${ }^{1} \cdot$ Frits van Osch ${ }^{1,3} \cdot$ Mariana Carla Stern $^{4} \cdot$ Xuejuan Jiang ${ }^{4}$. Eliane Kellen ${ }^{5}$. Chih-Ming Lu $^{6} \cdot$ Hermann Pohlabeln ${ }^{7}$. Gunnar Steineck ${ }^{8}$. James Marshall ${ }^{9} \cdot$ Mohamed Farouk Allam $^{10}$. Carlo La Vecchia ${ }^{11} \cdot$ Kenneth C. Johnson ${ }^{12}$. Simone Benhamou ${ }^{13} \cdot$ Zuo-Feng Zhang $^{14}$. Cristina Bosetti ${ }^{15}$. Jack A. Taylor ${ }^{16} \cdot$ Maurice P. Zeegers $^{1,2}$}

1 NUTRIM School for Nutrition and Translational Research in Metabolism, University of Maastricht, Universiteitssingel 40 (Room C5.564), 6229 ER Maastricht, The Netherlands

2 CAPHRI School for Public Health and Primary Care, University of Maastricht, Maastricht, The Netherlands

3 Institute of Cancer and Genomic Sciences, University of Birmingham, Birmingham, UK

4 Department of Preventive Medicine, University of Southern California, Los Angeles, CA, USA

5 Leuven University Centre for Cancer Prevention (LUCK), Louvain, Belgium

6 Department of Urology, Buddhist Dalin Tzu Chi General Hospital, Dalin Township, Chiayi County, Taiwan
7 Leibniz Institute for Prevention Research and Epidemiology-BIPS, Bremen, Germany

8 Clinical Cancer Epidemiology, Department of Oncology, Clinical Sciences, Sahlgrenska Academy, University of Gothenburg, Gothenburg, Sweden

9 Department of Cancer Prevention and Control, Roswell Park Cancer Institute, Buffalo, NY, USA

10 Department of Medical and Surgical Specialties, Radiological Sciences and Public Health, Section of Public Health and Human Sciences, University of Brescia, Brescia, Italy

11 Department of Clinical Medicine and Community Health, University of Milan, Milan, Italy 
12 Department of Epidemiology and Community Medicine, University of Ottawa, Ottawa, ON, Canada

13 INSERM U946, Variabilite Genetique et Maladies Humaines, Fondation Jean Dausset/CEPH, Paris, France Departments of Epidemiology, UCLA Center for Environmental Genomics, Fielding School of Public Health, University of California, Los Angeles (UCLA), Los Angeles, CA, USA
15 Laboratory of Oncology, Istituto di Ricerche Farmacologiche "Mario Negri" IRCCS, Milan, Italy

16 Epidemiology Branch and Epigenetic and Stem Cell Biology Laboratory, National Institute of Environmental Health Sciences, NIH, Research Triangle Park, NC, USA 